\title{
Preparative Scale Purification of Recombinant Proteins to Clinical Grade by Isotachophoresis
}

\author{
Anthony W. Stowers*, Kevin J. Spring and Allan Saul \\ Queensland Institute of Medical Research, Post Office, Royal Brisbane Hospital, 4029 Australia. \\ *Corresponding author (e-mail: tonyS@qimr,edu.au).
}

An electrophoretic procedure based on isotachophoresis has been developed for protein purification on a preparative scale in the 10 to $500 \mathrm{mg}$ range. The system is simple, uses well understood physical properties, does not need ampholyte spacers and is able to produce sterile products of clinical grade. We demonstrate the applicability of this apparatus for the purification of denatured recombinant proteins and complex mixtures of proteins. The system may also be used for both cationic and anionic purification of proteins in their native form. The system is scalable from analytical to preparative protein loads at consistently high protein yields and purity levels. Total protein loads may vary as much as 1000 fold with the use of interchangeable columns of varying diameter and constant length. At both preparative and analytical scales concentration of products at greater than $20 \mathrm{mg} / \mathrm{ml}$ are obtainable. Toxicological considerations are addressed with assays for endotoxin, acrylamide and SDS concentrations, as well as the prevention of covalent protein modification.

\section{Received 4 April 1995; accepted 13 October 1995}

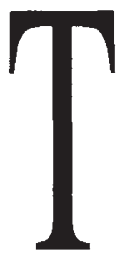
he production and purification of sufficient clinical grade material for trials poses a major hurdle to vaccine development. Here we present a simple method with broad application for the production of gram quantities of high grade protein, including sterile clinical grade material.

Rhoptry associated proteins 1 and 2 (RAP-1 and RAP-2) from Plasmodium falciparum are expressed in the parasite as a complex named QF3. Antibodies directed against these antigens have conferred protection against asexual parasite invasion of erythrocytes ${ }^{1-3}$ and are thus candidate proteins for vaccine development.

As recombinant proteins expressed in Escherichia coli, these two proteins were insoluble in most conditions except $6 \mathrm{M}$ guanidine- $\mathrm{HCl}$ or sodium dodecylsulfate (SDS). Purification of recombinant RAP- 1 and 2 by conventional methods to a level suitable for human trials has proved intransigent. Since the required purity could be met by analytical electrophoresis in SDS-PAGE, we investigated ways in which this could be scaled up to achieve the gram quantities required. We have developed a novel application of steady state stacking, or isotachophoresis ${ }^{4.5}$, to prepare gram quantities of RAP-2 and mg quantities of RAP-1 for use in human, rodent and monkey trials.

Isotachophoresis or ITP ("moving at the same speed") is a protein purification technique based on the electrophoresis of protein mixtures within a stacking gel (see references 4 and 5, and references quoted therein). Components within a stack in the gel may be individual proteins or peptides, excess reagents or endotoxin. Such components align in bands in order of decreasing electrophoretic mobility. The width of each band is proportional to both the quantity of the corresponding component and the buffer concentration. In theory, this has the unique advantage of increasing the resolution of a single protein by increasing sample load, as the regions of band interface become negligible compared to total band width.

Using a simple protocol we demonstrate the capacity of a denaturing ITP system to produce a high yield, high purity full length recombinant protein. Using detection assays for SDS and acrylamide adducts, we show low contamination levels and the lack of detectable amino acid side-chain modification of the product.

By applying the technique to more than one vaccine candidate we illustrate a general applicability for denatured purifications. We have also broadened the utility beyond denatured separations to the purification of proteins in their native forms with anionic and cationic native ITP, and to complex mixtures of proteins where the desired product is not one of the original major components.

\section{Results}

Apparatus. Figure 1A and 1B illustrate the apparatus we have used for isotachophoretic runs. A central glass column, with an interchangeable inner diameter (ID) from 3 to $19 \mathrm{~mm}$, is flanked by two buffer reservoirs containing electrodes. The column is pre-run, and the samples loaded in the vertical position. Subsequently, a $100^{\circ}$ column rotation allows sample elution from the upper end, with the column just off horizontal. Alternately, using sealed buffer compartments the column may be both loaded and eluted in the $100^{\circ}$ rotated position. A full description of the apparatus appears in International Patent Application PCT/AU94/00233, 1994.

All inlet ports of the apparatus are sealable with sterile filters (Fig. 1B) and the entire assembly is autoclavable. After autoclaving, monomer acrylamide is introduced to the column through a sterile filter and overlayed onto a sterile filtered $10 \% \mathrm{w} / \mathrm{v}$ sucrose cushion that provides a removable support for polymerization.

After polymerization, sterile buffers replace the sucrose support. Since all the inlet lines are sealed, buffer circulation and sample application can also be performed sterilely. This allows the entire assembly to remain sterile during electrophoresis and elution to prevent endotoxin production during a run.

Elution occurs through a small capillary tube running to the anode face of the gel. The proteins in the stack are highly concentrated, and the nearly vertical gel face allows density driven elution. The eluted sample is divided into discrete blocks in the capillary tube by introducing air bubbles into the line at $50 \%$ of the elution rate. These bubbles reduce sample mixing in the elution line by over $50 \%$ (data not shown).

During development of the prototype, fluid flow through the electrode chambers was monitored by following dye injected with the electrode buffers. This led to the design of a number of features to minimize heating in the elution chamber, resulting in the elimination of convection currents which interfere with sample elution and cause the contamination of the product with electrolysis by-products. These 
STACKING

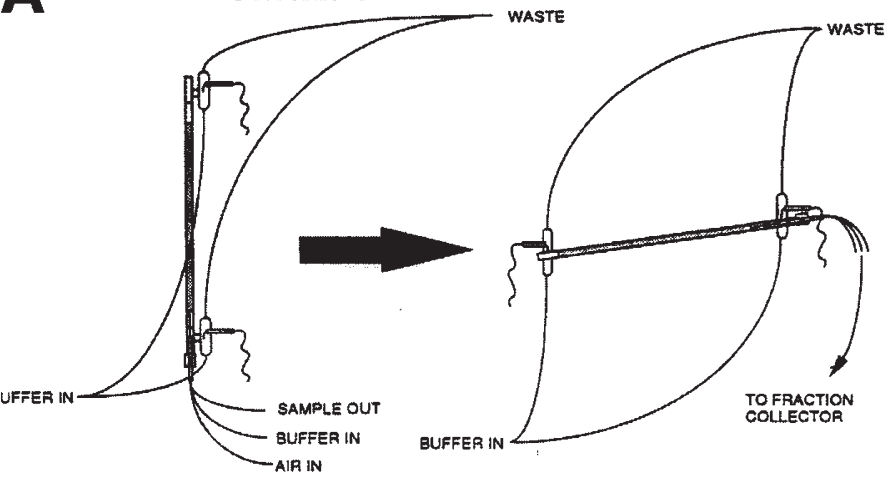

B

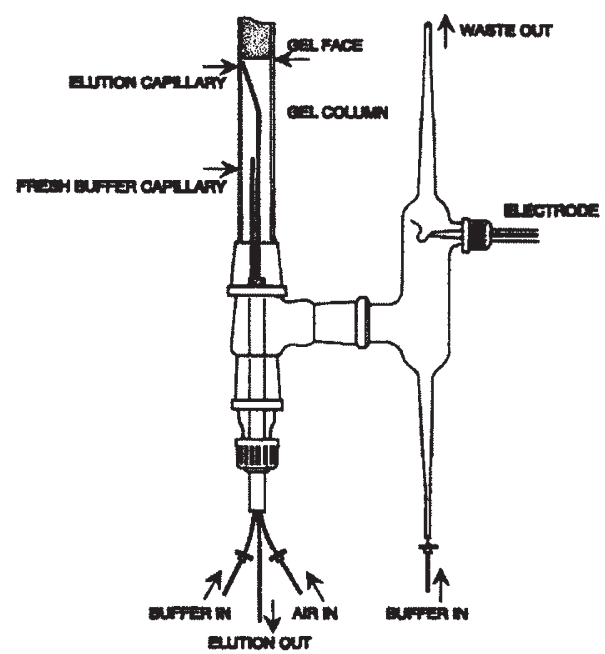

FIGURE 1. Schematic of the ITP apparatus. (A) The apparatus and operational procedures are described in the text. (B) Enlargements of the elution electrode chamber illustrate the protection of all inlet ports with sterile filters for the production of clinical grade material (the upper electrode chamber is essentially the same).

include locating the terminal electrode so that the path of the by-products of electrolysis at the anode electrode (concentrated $\mathrm{HCl}$ amongst others) is directly into the waste line. A narrowing of the electrode chamber around the platinum electrode itself increases the flow rate past the electrode into the waste line and aids in this process. It was important to use a wide bore between the electrodes and gel surfaces to minimize the voltage drop and hence power dissipation in these chambers.

A sufficient flow rate of fresh buffer to both electrode chambers, to reinforce the above two effects and maintain buffering $\mathrm{pH}$ at the gel face, was empirically determined. At the elution end of the assembly, fresh buffer is also introduced directly to the gel face by a capillary tube (shorter than the elution capillary). Substantial yield losses will result if these measures are not taken.

When denaturing ITP is performed under our standard conditions, an optimal load for a $19 \mathrm{~mm}$ ID column is $500 \mathrm{mg}$ total protein, with power scaled to protein size. These limits are proportionally scalable for columns with smaller IDs.

The minimum possible collection rate is equal to the rate at which protein is being swept off the elution face of the gel. This minimum theoretical rate can be calculated by multiplying the migration speed of the protein band by the cross sectional area of the column. Collecting at this rate allowed product concentrations of greater than $20 \mathrm{mg} / \mathrm{ml}$ to be achieved. We routinely perform runs at 10 times the minimum theoretical rate to give product concentrations of 1 to $2 \mathrm{mg} / \mathrm{ml}$. This minimizes loss of resolution in the fraction collector and other parts of the elution path.

The maximum amount of mixing between protein bands within the stack, and hence the maximum contamination levels, were determined by performing ITP on the naturally coloured haemoglobin protein. Current was halted during the run and the time for all eluted protein to be removed was measured. In $19 \mathrm{~mm}$ diameter gels the maximum mixing time at the elution face was 30 seconds and less in smaller diameter gels.

Managing chemical adduct formation and product contamination. To prevent reaction of acrylamide with pro- teins during electrophoresis, we ensued the abrace of acrylamide monomer. We developed an assay for measuring monomer acrylamide via HPLC detection at $208 \mathrm{~nm}$. The assay could detect less than 18 pmoles of acrylamide. This assay was used to measure the rate of free monomer acrylamide scavenging by thioglycolic buffer at three temperatures. Scavenging half-lives of 20,30 and 45 minutes were found at 50,40 and $30^{\circ} \mathrm{C}$ respectively. Pre-running the columns overnight in thioglycolic buffer removes greater than $99.99997 \%$ of the unpolymerized acrylamide.

Model ITP denaturing system: BSA. SDS-PAGE of eluted fractions showed BSA containing fractions (Fig. 2, fractions 60-130) separated from low molecular weight contaminants (Fig. 2, fractions 46-58). Quantitative densitometry of these fractions demonstrated a BSA purity of $>95 \%$ in pooled peak fractions, compared with $72 \%$ in the starting material. There was a total exclusion of contaminants $<50 \mathrm{kDa}$ and $>80 \mathrm{kDa}$ from the pooled peak material. Protein recovery, as a percentage of total BSA loaded, was $80 \%$.

The pooled and dialyzed fractions had $0.10 \% \mathrm{w} / \mathrm{v}$ SDS (or $1 \mathrm{mg} \mathrm{SDS} / \mathrm{mg}$ protein) and an acrylamide content below the limiting value of the assay sensitivity of $0.000005 \% \mathrm{w} / \mathrm{v}$. No covalently modified amino acid residues were detected by amino acid analysis, whereas there was close to quantitative recovery of carboxyethyl cysteine from hydrolysed BSA purified using a conventional binary Tris- $\mathrm{HCl} /$ Tris-glycine buffer system without column pre-electrophoresis.

Fraction 51 from the first ITP run, combined with prestained molecular weight markers, was loaded directly onto a $3 \mathrm{~mm}$ ID ITP column. SDS-PAGE from this second ITP run clearly showed four major bands (Fig. 3), none of which were visible in the original Fraction V BSA. Of these, $10 \mu \mathrm{l}$ from fraction 41 containing a protein with an apparent molecular weight of $30 \mathrm{kDa}$ was sequenced, and the $\mathrm{N}$ terminus corresponded to amino acid 25 of BSA (GenBank Locus ABBOS).

Purification of malarial vaccine candidates. RAP-2 is a $42 \mathrm{kDa}$ protein of Plasmodium falciparum. The form used here was expressed as a $45 \mathrm{kDa}$ recombinant protein in $E$. coli, with a hexaHis $\mathrm{N}$-terminal, and passed over a $\mathrm{Ni}^{++}$chelating resin as an initial purification step ${ }^{6}$. Figure $4 \mathrm{~A}$ shows the 

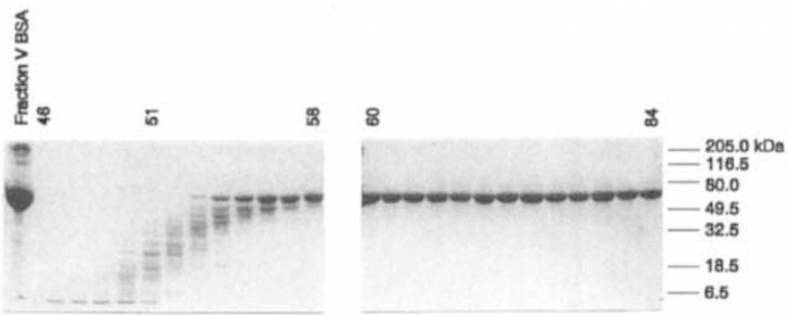

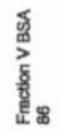

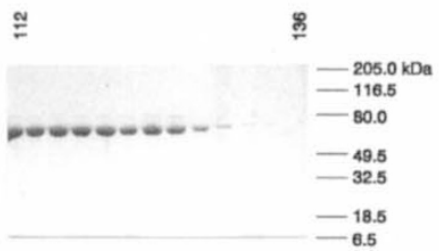

FIGURE 2. 10\% SDS-PAGE analysis of fractions obtained from the removal of contaminants from a commercial preparation of bovine serum albumin. $500 \mathrm{mg}$ (10 ml of Fraction V BSA) were mixed with $50 \mu l$ pre-stained protein size markers and loaded onto a $5 \%$ ITP column $19 \mathrm{~mm}$ ID $\times 500 \mathrm{~mm}$ as described in the text. Aliquots of the starting material $(1 \mu$ of Fraction V BSA) are compared with $1 \mu$ l aliquots of every fraction (first gel) or every second fraction (gels 2 to 4) eluting from the ITP run (1 ml total fraction volume, 46 to 136).

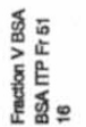

ละ
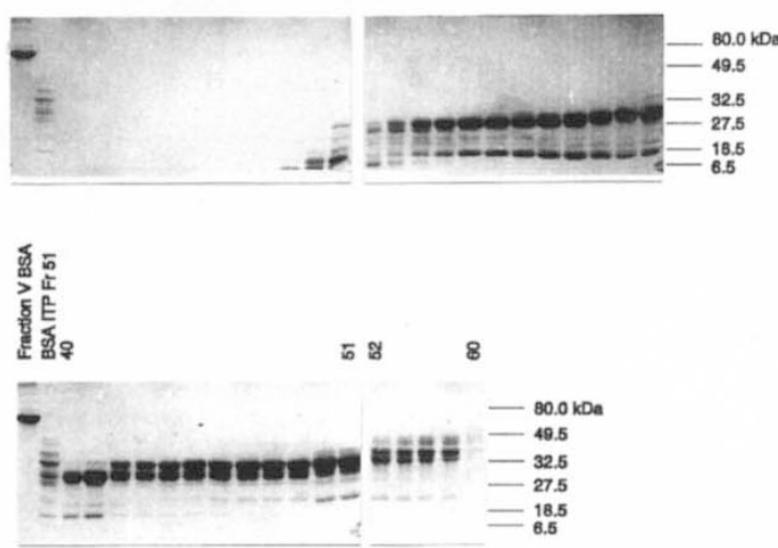

FIGURE 3. $12.5 \%$ SDS-PAGE analysis of the purification of minor contaminants in a commercial preparation of bovine serum albumin. Commercial bovine serum albumin (BSA Fraction V) was first separated into fractions containing predominantly low molecular weight contaminants and pure bovine serum albumin in a $5 \%$ ITP run (Fig. 2). Fraction 51 from this first run was then mixed with $2 \mu l$ of prestained protein size markers and re-electrophoresed on a $3 \mathrm{~mm}$ ID $\times 500 \mathrm{~mm}$ ITP column and $64 \mu$ fractions collected. $1 \mu \mathrm{l}$ of both the original Fraction V BSA and fraction 51 from the first ITP run are compared with $4 \mu$ l of every protein containing fraction (gels 1 to 3 ) or every second (gel 4) from the second ITP run (fractions 16 to 60 ). The $20 \mathrm{kDa}$ band eluting in fractions 30 to 41 , and the $27.5 \mathrm{kDa}$ band eluting in fractions 47 to 58 are from pre-stained markers added to the original ITP run. These bands show an anomalous migration when comparing the ITP and analytical runs.

ITP. Since the band width of each component is proportional to the quantity loaded, the elution position and the number of fractions containing a particular component, depends both on the amount of material with a faster mobility and the amount of that component. In this case, there were forty fractions containing RAP-1 fragments and 90 fractions containing full length product which gives an estimate of its initial purity of $90 / 140$ or $64 \%$.

The yield was $71 \%$ of full length RAP-1 loaded. Sequencing of seven of the minor bands, purified in the early fractions, confirmed that they were RAP-1 derived polypeptides with unblocked $\mathrm{N}$-terminals.

Interestingly, increasing the RAP-1 protein load caused the loss of proteins from the rear of the stack and a subsequent loss of yield and resolution. Chasing the protein stack with SDS or lower $\mathrm{pH}$ buffers, or adding dithiothreitol to the trailing buffer failed to improve recovery, indicating that the protein loss was not a result of protein precipitation due to oxidisation, SDS removal or the higher $\mathrm{pH}$ of the trailing buffer allowing protein-protein interactions. However lowering the applied current prevented the protein loss. For RAP-1 it was apparent that a critical current flux of greater than $0.03 \mathrm{~mA} / \mathrm{mm}^{2}$ resulted in a reduction in yield.

Endotoxins from host bacteria were also electrophoretically separated and shown not to contaminate the product by LAL (limulus amoebocyte lysate) test. For RAP-1 and RAP2 no $E$. coli material was detectable in the product by immunoblot with polyclonal rabbit antisera against $E$. coli, despite extensive contamination in the ITP starting material 

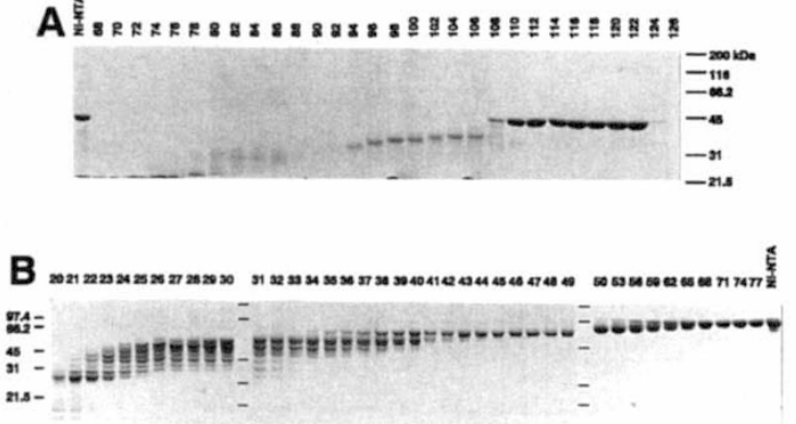

FIGURE 4. (A) SDS-PAGE of fractions eluting from the isotachophoretic purification of recombinant RAP-2. $50 \mathrm{mg}$ were loaded onto a $7.5 \%$ ITP column $10 \mathrm{~mm}$ ID $\times 500 \mathrm{~mm}$ as in the text. $2 \mu \mathrm{l}$ of every $500 \mu \mathrm{l}$ fraction were loaded on $10 \%$ gels (fractions 68 to 126). The starting material (1 $\mu \mathrm{l}$ run in lane NiNTA) was purified prior to the ITP by Ni-NTA chromatography. (B) SDS-PAGE of fractions eluting from the isotachophoretic purification of recombinant RAP-1. $34 \mathrm{mg}$ was loaded onto a 4\% ITP column $10 \mathrm{~mm}$ ID $\times \mathbf{5 0 0} \mathrm{mm}$ as in the text. $1 \mu \mathrm{l}$ of $\mathbf{1 0 0}$ $\boldsymbol{\mu l}$ fractions was loaded (fractions 20 to 77 ) and compared to the starting material ( $1 \mu \mathrm{l}$ run in lane Ni-NTA) which was purified prior to ITP by Ni-NTA chromatography. RAP-1 containing fractions were 71 to 122 . Sizes of the molecular weight standards are indicated by straight lines.

(data not shown).

Native ITP. Figures $5 \mathrm{~A}$ and $5 \mathrm{~B}$ demonstrate protein purification using anionic and cationic native ITP systems. In both systems a similar protein load of whole Human Serum combined with IEF markers was used. One of the IEF marker proteins was Human hemoglobulin. This protein has a quaternary subunit structure, and under native ITP conditions it behaves as a $64.5 \mathrm{kDa}$ protein with a $\mathrm{pI}$ of 7.1 to 7.5. In analytical SDSPAGE gels, it runs as a single band of approx. $15.5 \mathrm{kDa}$ (the $\alpha$ subunits $15.1 \mathrm{kDa}$ and the $\beta$ subunits 15.9 $\mathrm{kDa})$.

The order of elution for the anionic system (Fig. 5A) is $\beta$-Lactoglobulin B (18.4 kDa, pI 5.1); Human serum albumin (66.4 kDa, pI 6.0), which initially co-eluted with a lower molecular weight Human Serum protein $(\approx 60 \mathrm{kDa})$, and then a higher molecular weight Human Serum protein $(\approx 100 \mathrm{kDa})$. Human hemoglobulin $(62 \mathrm{kDa}$, pI 8.3$)$, Cytochrome c (12.2 kDa, pI 9.6), Equine myoglobin (16.8 $\mathrm{kDa}, \mathrm{pI} 9.0$ ), Phycocyanin ( $232 \mathrm{kDa}, \mathrm{pI} 4.45$ to 4.75 ) and both Bovine and Human carbonic anhydrase $(28.5$ and $28.6 \mathrm{kDa}$, pI 8.9 and 7.5 ) were excluded from the protein stack.

Conversely for the cationic system (Fig. 5B) the order of elution was Cytochrome c; Human hemoglobulin; Equine myoglobin; Bovine and Human carbonic anhydrase; Human serum albumin; an $\approx 100 \mathrm{kDa}$ Human serum protein; some lower molecular weight Human serum proteins and $\beta$ Lactoglobulin B. Excluded from the protein stack was Phycocyanin.

Despite a serum load less than $2 / 3$ that of the cationic system, the anionic system protein stack occupied a volume in the column greater than twice that of the cationic stack, and travelled 3 times as fast. Optimal purity depends on the protein of interest, but for Human serum albumin a high degree of purity was obtained.

\section{Discussion}

As demonstrated with BSA (Fig. 2 and 3), denatured ITP offers a relatively simple method for the purification of up to

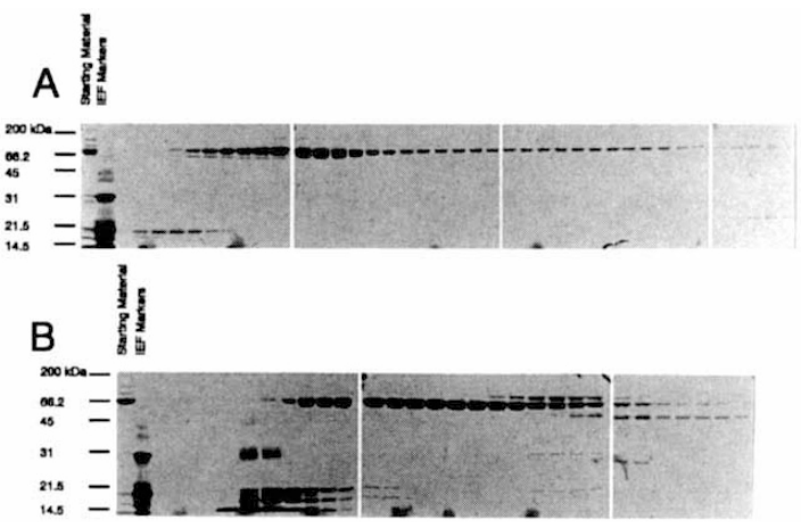

FIGURE 5. (A) SDS-PAGE analysis of fractions obtained from an anionic native ITP purification of human serum combined with IEF Markers performed in a $7 \% 3 \mathrm{~mm}$ ID $\times 500 \mathrm{~mm}$ column. 0.25 $\mu$ l samples of the starting material are compared with $6 \mu \mathrm{l}$ aliquots from $115 \mu$ fractions eluted from the native ITP run. (B) SDS-PAGE analysis of fractions obtained from an cationic native ITP purification of human serum combined with IEF Markers, performed in a $5 \% 3 \mathrm{~mm}$ ID $\times 500 \mathrm{~mm}$ column. $0.25 \mu \mathrm{l}$ samples of the starting material are compared with $6 \mu \mathrm{l}$ aliquots from $115 \mu \mathrm{l}$ fractions eluted from the native ITP run.

$500 \mathrm{mg}$ of protein per run. The high load capacity makes ITP an attractive technique as it works optimally at these loads. Most other electrophoretic systems, although able to equal ITPs purity levels, cannot meet its capacity.

Previous versions of ITP required the gel matrix to be sliced and the protein then eluted for recovery ${ }^{4}$, or have required varying degrees of complexity to allow sufficient resolution at higher load capacities, including the use of non-solid electrophoresis supports ${ }^{7}$. Elution of the product and the elimination of the need for ampholyte spacers between the protein bands in the stack are major factors in making this method of ITP applicable beyond the range of small-molecule separation.

Protein band mobility within the stack is proportional to applied current rather than voltage, so all ITP is performed under constant current conditions. To allow for consistent performance on differing quantities of the same initial protein composition, current flux $\left(\mathrm{mA} / \mathrm{mm}^{2}\right)$ is kept approximately constant between gels of differing diameter (total power output permitting). Protein mobilities between all three diameter gels are thus kept approximately constant, allowing elution conditions to be optimized. This means that initial optimization runs can be performed on analytical scales, before scaling to preparative quantities with larger diameter columns at the same load $/ \mathrm{mm}^{2}$ with similar resolutions. The elution conditions themselves are flexible, with product concentrations from less than $1 \mathrm{mg} / \mathrm{ml}$ to greater than $20 \mathrm{mg} / \mathrm{ml}$ achievable.

None of the ITP runs performed used any cooling mechanisms. The low mobility of the trailing buffer ion (glycine) causes the greatest voltage drop between the trailing discontinuity of the stack and its final component protein. Hence the greatest heat generation occurs after the proteins have passed that area of the gel, obviating the need for a cooling jacket on the column even at very high protein loads in denaturing gels.

ITP allows proteins to be loaded in the presence of SDS and $\beta$-mercaptoethanol, overcoming solubility problems. Excess reagents (acrylamide and SDS) were shown not to con- 
taminate eluted product as they in turn are electrophoretically separated from the protein.

We have also shown the use of a unique tertiary buffer system of Tris-HCl, Tris-thioglycolic acid, and Tris-glycine. A complete exchange of the initial Tris- $\mathrm{HCl}$ gel buffer for the Tris-thioglycolic acid buffer in the pre-running step is possible because the behavior of the system is essentially determined by the ionic composition of the gel when it is cast, even if the original ions are completely replaced prior to protein loading. The only way in which ions can be altered is by electrophoresing new ions into place, and the mobility and concentration of these is fixed by the preceding ionic composition. In this way the $\mathrm{pH}$ and ionic strength of the Tris- $\mathrm{HCl}$ buffer determines the later concentration of proteins in the stack despite pre-electrophoresis. This tertiary buffer system permits the efficient scavenging of acrylamide monomers, preventing product modification.

The composition of the initial protein mix loaded onto an ITP column is critical for optimum product resolution. Resolution may be improved by increasing the relative quantity of the protein of interest loaded, but conversely may be lessened if the total volume of the protein stack on the column is increased excessively. Increasing the relative quantity of the protein of interest improves resolution by increasing that protein band's volume:interface ratio within the gel, reducing mixing during elution. There is a simple relationship between total protein load and resolution. A mixture of two proteins in the gel will stack if the last molecule of the protein with the higher mobility overtakes the first molecule of the protein with slower mobility before the end of the gel is reached. As a first approximation, for the major components this occurs if the relative difference in mobility between two proteins is greater than the proportion of the gel occupied by the protein. The volume of protein once stacked, is proportional to both the quantity of protein and the concentration of the buffer incorporated in the gel on casting, so provided there is sufficient protein in a single band to give a high volume to interface ratio, the system can be readily optimized for capacity or resolution by altering the cross-sectional area of the column or its length (to alter gel volume) or buffer concentration. However there are limits to increasing the column loading by increasing buffer concentration as there are limits to the protein concentration which can be effectively separated. Under our denaturing buffer concentrations, the protein concentration within the stack is approximately 30 $\mathrm{mg} / \mathrm{ml}$, and concentrations much above this cause distortions within the gel and depending on the current flux, precipitation of proteins on the column.

We have further extended the utility of ITP with complex protein mixtures. We have shown that when the desired product is not one of the original sample's main component proteins, two passes through ITP will give an end product of high purity. We purified originally undetectable components from a commercial BSA protein (Fig. 3). In spite of two electrophoresis runs totalling several days, no detectable modification of the product occurred as judged by amino acid analysis and the ability to sequence the $\mathrm{N}$-terminal.

As we showed with RAP-1, since ITP allows the stacking of all protein components in order of size at uniform concentrations within the gel, minor incomplete species of the recombinant material as well as the full-length protein could be purified. Species that were undetectable in the starting material (Fig. 4B, lane Ni-NTA) are thus purified at concentrations comparable to the full length protein (Fig. 4B, lanes 2 to 77). This allows these incomplete polypeptides to be recovered for a range of independent applications. For instance we have used these peptides to screen polyclonal sera to map the epi- topes in RAP-16.

We have also investigated native ITP. For proteins with $\mathrm{pI}$ below 7.5 this is a relatively simple process since these proteins will be negatively charged under standard buffer systems ( $\mathrm{pH} 7.5-9.0$ ), see Figure 5A. For proteins with higher pIs, cationic ITP is required. The acidic nature of the buffers requires a photopolymerised gel, but beyond that no other modification to the standard method is necessary (Fig. 5B).

While the system can be used with many buffer systems, we believe that this process will be particularly useful for the type of situation illustrated with the RAP-1 and RAP-2 proteins. These proteins are only soluble in highly denaturing conditions where more conventional high resolution procedures such as ion exchange and reverse phase chromatography are impossible. The ITP process described allows the rapid gram scale production of clinical grade material required for preliminary evaluation of efficacy (in our case, immunogenicity of the denatured material). In some cases, this procedure may also be suitable for the production of the final product. For example, vaccines for human use commonly contain 10 to $100 \mu \mathrm{g}$ of antigen per dose. We estimate that one person could operate at least 10 of the $19 \mathrm{~mm}$ columns in parallel giving a weekly throughput of $>5 \mathrm{~g}$ of protein or a production of 2.5 to 25 million vaccine doses per year. Larger columns would further increase the throughput and we have used a $27 \mathrm{~mm} \times 1 \mathrm{~m}$ column to purify $2 \mathrm{~g}$ loads of BSA. However there are major constraints imposed by the mechanical stresses in the acrylamide and dissipation of heat which suggest that increased throughput may be more efficiently obtained by running many smaller columns in parallel.

\section{Experimental Protocol}

Protein sample preparation. $10 \mathrm{ml}$ of $50 \mathrm{mg} / \mathrm{ml}$ fraction $\mathrm{V}$ bovine serum albumin (BSA), 10\% w/v SDS, $124 \mathrm{mM}$ Tris, $92 \mathrm{mM}$ thioglycolic acid $\mathrm{pH} 7.5$, were placed into dialysis membrane and dialyzed at $22^{\circ} \mathrm{C}$ against $500 \mathrm{ml}$ of thioglycolic buffer $(124 \mathrm{mM}$ Tris, $92 \mathrm{mM}$ thioglycolic acid). $50 \mu \mathrm{l}$ of pre-stained molecular weight markers (Broadrange, BioRad, USA) were added to the retentate. Recombinant RAP-1 and RAP-2 were expressed from Escherichia coli and an initial Ni-NTA purification step performed as described ${ }^{6}$. For anionic and cationic native ITP, $4 \mathrm{ml} \mathrm{O}^{+}$human serum supplied by the Australian Red Cross was dialyzed into $150 \mathrm{mM}$ Tris-HCl $\mathrm{pH} 7.5$.

Denatured ITP. Denaturing ITP was performed in cylindrical columns of varying internal diameters $(19,10$ or $3 \mathrm{~mm}$ depending on the protein load) and $500 \mathrm{~mm}$ in length. Denaturing polyacrylamide gels of varying percentages of 29:1 acrylamide:bisacrylamide were prepared in $150 \mathrm{mM}$ Tris- $\mathrm{HCl} \mathrm{pH} 7.5$, filtered in a $0.22 \mu \mathrm{m}$ disposable filters then degassed by sonication under $900 \mathrm{mbar}$ vacuum for 10 minutes. Polymerization was initiated with $0.015 \% \mathrm{w} / \mathrm{v}$ ammonium persulphate and $0.05 \%$ v/v TEMED. Columns were pre-electrophoresed with thioglycolic buffer for 36 hours at $20 \mathrm{~mA}$ constant current for the $19 \mathrm{~mm}$ ID gels, then 2 hours at $60 \mathrm{~mA}$ to heat the column ensuring that any remaining traces of monomer acrylamide reacted with the thioglycolate prior to loading. $10 \mathrm{~mm}$ and $3 \mathrm{~mm}$ ID gels were pre-run 18 hours at $10 \mathrm{~mA}$ and $2.0 \mathrm{~mA}$ constant current respectively. During both pre-electrophoresis and the actual run the electrode chambers were continuously flushed with fresh buffer at $65 \mathrm{ml} / \mathrm{hr}$ (19 and $10 \mathrm{~mm}$ ID) or $6.5 \mathrm{ml} / \mathrm{hr}$ ( $3 \mathrm{~mm}$ ID) at the cathode end and $120 \mathrm{ml} / \mathrm{hr}$ or $12 \mathrm{ml} / \mathrm{hr}$ at the anode end Columns were allowed to cool for one hour with no current prior to sample loading, and the trailing electrode (cathode) chamber buffer was changed to $127 \mathrm{mM}$ Tris, $90 \mathrm{mM}$ glycine, $0.01 \% \mathrm{w} / \mathrm{v}$ SDS. Denatured gels were loaded with $500 \mathrm{mg}, 50 \mathrm{mg}$ or $6 \mathrm{mg}$ total protein (unless otherwise stated), dialyzed into thioglycolic buffer. In some instances $2 \% \mathrm{w} / \mathrm{v}$ sucrose and $1 \% \mathrm{v} / \mathrm{v} \beta$-mercaptoethanol were added. Electrophoresis was carried out for 30 hours at $20 \mathrm{~mA}$ constant current (19 mm ID); at $10 \mathrm{~mA}$

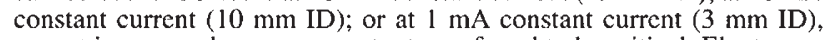
except in cases where power output was found to be critical. Eluate was collected into $160 \times 1 \mathrm{ml}(1 \mathrm{~min})$ fractions, $150 \times(1 \mathrm{~min}) 500 \mu \mathrm{l}$ fractions, or $80 \times(1 \mathrm{~min}) 64 \mu \mathrm{l}$ fractions (calculated to be approximately a 1 in 8 dilution of the eluting material for each column size).

Native ITP. Anionic and cationic native ITP were carried out in $3 \mathrm{~mm}$ ID $\times 500 \mathrm{~mm}$ length columns, with $7 \%$ or $5 \% \mathrm{~T}$ (total monomer, acrylamide + bisacrylamide at 29:1) respectively. Neither system was preelectrophoresed. Anionic native ITP was performed with the same leading and trailing buffers as detailed above for denaturing systems, without the SDS (150 mM Tris- $\mathrm{HCl} \mathrm{pH} 7.5$ leading, $25 \mathrm{mM}$ Tris, $200 \mathrm{mM}$ glycine trailing). Cationic native ITP gels were prepared in a leading buffer of 60 $\mathrm{mM}$ potassium hydroxide, $121.8 \mathrm{mM}$ acetic acid $\mathrm{pH}$ 5.0. These gels were 
photopolymerized, catalyzed by $0.01 \% \mathrm{w} / \mathrm{v}$ ammonium persulfate and $0.0008 \% \mathrm{w} / \mathrm{v}$ riboflavin, under fluorescent lamps. Cationic terminating buffer was $202 \mathrm{mM}$ glycine, $190 \mathrm{mM}$ acetic acid pH 4.5. For both systems, samples were loaded in each leading buffer. Samples consisted of $300 \mu \mathrm{l}$ of $1 \times$ leading buffer, $3 \%$ Sucrose, $1.32 \mathrm{mg}$ IEF markers (BioRad, USA) and either 1.3 or $2.0 \mathrm{mg}$ of dialyzed human serum (anionic and cationic respectively). Electrophoresis was performed at $0.25 \mathrm{~mA}$ constant current for 12 or 30 hours (anionic or cationic), prior to the elution of $80 \times(1 \mathrm{~min}) 64 \mu \mathrm{l}$ fractions.

Fraction analysis. Fractions were analyzed by SDS-PAGE', and purity and yields quantitated by densitometry (Molecular Dynamics Computing Densitometer and ImageQuant software, USA). Fractions of highest purity were pooled, dialyzed 1 in 500,000 against $150 \mathrm{mM}$ Tris- $\mathrm{HCl} \mathrm{pH} \mathrm{7.5,0.05 \%} \mathrm{w/v} \mathrm{SDS} \mathrm{at} 4^{\circ} \mathrm{C}$. Spectral and amino acid analysis was performed to determine concentrations and product modifications.

Monomer acrylamide assays and free SDS determination. To determine the levels of monomer acrylamide, $25 \mu 1$ samples were loaded onto a Whatman Partisil 10 ODS-2 HPLC analytical column with a C4 precolumn and eluted with water at a flow rate of $2 \mathrm{ml} / \mathrm{min}$ with a detector sensitivity of 0.002 absorbance units at $208 \mathrm{~nm}$. Concentration of acrylamide present in the sample was determined by comparison with acrylamide standards. Between runs, the precolumn was regenerated with a $0-100 \%$ acetonitrile gradient. This permitted the assay of acrylamide in protein solutions by ensuring proteins were removed before the ODS-2 column. Rates of acrylamide scavenging by thioglycolic acid were determined by incubating $100 \mu \mathrm{g} / \mathrm{ml}$ acrylamide in thioglycolic buffer at 50 , 40 and $30^{\circ} \mathrm{C}$ and assaying aliquots for free acrylamide at various time points. Determination of the SDS concentration associated with the protein in the dialyzed pools was done according to the procedure of Waite and Wang ${ }^{10}$.

Protein sequencing. Protein samples were sequenced using a model 473A Applied Biosystems protein sequencer, either directly by loading a sample aliquot into a Prospin cartridge (Applied Biosystems, USA), or sequenced after SDS-PAGE and electro-blotting to polyvinylidine diflouride membranes (Immobilon-psq, Millipore, USA) and excising band of interest.

Amino acid analysis. Proteins were hydrolyzed in vapor phase $6 \mathrm{M}$ $\mathrm{HCl}, 0.1 \%$ phenol at $110^{\circ} \mathrm{C}$ for 24 hours then analyzed by pre-column derivatization with phenylisothiocyanate. Proteins purified on acrylamide, which had not been pre-electrophoresed, contained a novel peak in the amino acid analysis which eluted slightly behind carboxymethyl cysteine. A standard for this peak was prepared by reacting glutathione with acrylamide, purifying the adduct by reverse phase HPLC, followed by acid hydrolysis. A new peak, assumed to be carboxyethyl cysteine, was present in the analysis of the hydrolysate. This co-eluted with the novel peak in protein hydrolysates. A relative absorbance for this carboxyethyl cysteine was determined by comparison with the peak heights of the glycine and glutamate present in the modified glutathione hydrolysates.

\section{Acknowledgments}

We would like to gratefully acknowledge Drs. Dieter Gillessen and Bela Takacs of F. Hoffmann La-Roche, Basel for supplying the recombinant RAP-1; Dr. Peter Kennedy of Biotech Australia, Sydney and Peter Schoofs of CSL Itd, Melbourne for their supplies of recombinant RAP-1 and RAP-2. This work was financially supported by grants provided by the Australian malarial vaccine development joint venture SARAMANE, AMRAD Itd, and the Australian National Health and Medical Research Council.

\section{References}

1. Ridley, R. G., Takacs, B., Lahm. H., Delves, C. J., Goman, M., Certa, U., Matile, H., Woollett, G. R. and Scaife, J. G. 1990. Characterisation and sequence of a protective rhoptry antigen from Plasmodium falciparum. Mol. Biochem. Parasitol. 41:125-134.

2. Saul, A., Cooper, J., Hauquitz, D., Irving, D., Cheng, Q., Stowers, A. and Limpaiboon, T. 1992. The 42-kilodalton rhoptry-associated protein of Plasmodium falciparum. Mol. Biochem. Parasitol. 50:139-150.

3. Ridley, R. G., Takacs, B., Etlinger, H. and Scaife, J. G. 1990. A rhoptry antigen of Plasmodium falciparum is protective in Saimiri monkeys. Parasitology 101: 187-192.

4. Baumann, G. and Chrambach, A. 1976. Gram-preparative protein fractionation by isotachophoresis: Isolation of human growth hormone isohormones. Proc. Nat. Acad. Sci. USA 73:732-736.

5. Holloway, C. J. and Battersby, R. V. 1984. Preparative Isotachophoresis. Methods Enzymol. 104:281-301.

6. Stowers, A., Prescott, N., Cooper, J., Takacs, B., Stueber, D., Kennedy, P. and Saul, A. 1995. Immunogenicity of recombinant Plasmodium falciparum rhoptry associated proteins 1 and 2 . Parasit. Immunol. In press.

7. Righetti, P. G., Faupel, M. and Wenisch, E. 1992. Preparative electrophoresis with and without immobilized $\mathrm{pH}$ gradients, p. 159-200. In: Advances in Electrophoresis. Chrambach, A., Dunn, M. J. and Radola, B. J. (Eds.). VCH Publishers, New York, NY.

8. Moos, M. Nguyen, N. Y. and Liu, T.-Y. 1988. Reproducable high yield sequencing of proteins electrophoretically separated and transferred to an inert support. J. Biol. Chem. 263:6005-6008.

9. Laemmli, U. K. 1970. Cleavage of structural proteins during the assembly of the head of the bacteriophage T4. Nature 277:680-682.

10. Waite, J. H and Wang C.-Y. 1975. Spectrophotometric measurement of dodecyl sulfate with basic fuchsin. Anal. Biochem. 70:279-280.

\section{Erratum}

Due to a printing error, Figure 5 in Boublik, Y., Di Bonito, P. and Jones, I.M., 1995, "Eukaryotic virus display: Engineering the major surface glycoprotein of the Autographa california nuclear polyhedrosis virus (AcNPV) for the presentation of foreign proteins on the virus surface." Bio/Technology 13:10791084, was incorrect. The correct figure and legend are reproduced below.

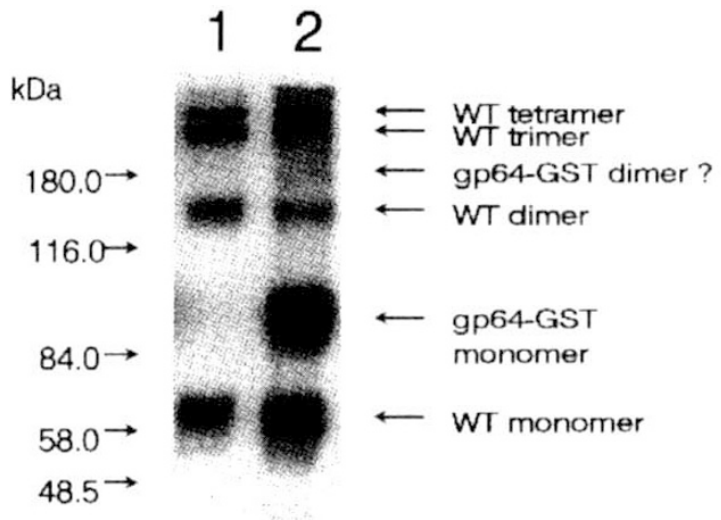

FIGURE 5. Oligomers of gp64. Samples were $p$ rocessed for Western blot as described. Lane 1: AcNPV wild type. Lane 2: AcGSGP-1. The positions of the wild type oligomer forms are indicated, as are the molecular weight markers $(\mathrm{kDa})$. The Western blot was developed with the AcV5 anti-gp64 MAb.

\section{EPITOPE MAPPING}

\section{$999 \$$}

\section{Monoclonal Antibodies and Polyclonal Sera}

Development of doy $\mathrm{P}$. Peptide Scans, Mutational Epitope Analysis. Hyturtogy Scans, b/L/tyolic Peptide Libraries, t. Finding

jerin!
Jerini Bio Tools $\mathrm{GmbH}$ Rudower Chaussee 5

12489 Berlin, Germany
Phone: $+49-30-6392-6392$ Fax: $+49-30-6392-6395$ biotools@jerini.fta-berlin.de
Write in No. 408 on Reader Service Card

Keep pace with the changing biotechnology marketplace.

\author{
Whatever aspect of biotechnology \\ concerns you, you'll find it covered \\ best in BIO/TECHNOLOGY. \\ Subscribe to BIO/TECHNOLOGY, \\ a leading journal in its field.
}

Start your subscription today!

See the insert card in this issue for details!

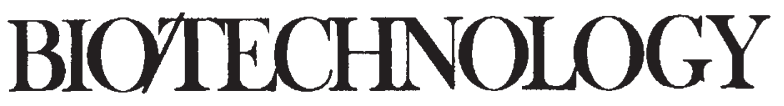

